\title{
Morphometric Measurements of Cadaveric Thoracic Spine in Indian Population and Its Clinical Applications
}

\author{
Roop Singh1, Sunil Kumar Srivastva², Chittode Sachudanandam Vishnu Prasath, \\ Rajesh Kumar Rohilla', Ramchander Siwach¹, Narender Kumar Magu' \\ ${ }^{1}$ Department of Orthopaedic Surgery, Paraplegia and Rehabilitation, \\ Pt. B. D. Sharma Post Graduate Institute of Medical Sciences, Rohtak, Haryana, India \\ ${ }^{2}$ Department of Anatomy, Pt. B. D. Sharma Post Graduate Institute of Medical Sciences, Rohtak, Haryana, India
}

Study Design: Analysis of morphometric data obtained from direct measurements of 100 cadaveric thoracic spines in Indian population.

Purpose: To collect a base line morphometric data and analyze it in reference to the musculoskeletal anatomy and biomechanics of the spine; implants and instrumentations; and to suggest the requisite modification in spinal surgery instrumen tations.

Overview of Literature: Most of the previous studies in the world literature have focused primarily on the parameters of the pedicle and to the authors' knowledge; no study has been published from the Indian subcontinent reporting a detailed mor phometry of the thoracic spine.

Methods: One thousand and two hundred thoracic vertebrae were studied by direct measurements for linear and angular dimensions of the vertebral body, spinal canal, pedicle, and spinous and transverse processes in 100 human cadavers.

Results: Thirty-five point five percent of all the pedicles; $71 \%$ of $\mathrm{T} 5$ pedicles; $54.6 \%$ of all the female pedicles; and $94.4 \%$ of the $\mathrm{T} 5$ pedicles in females were smaller than $5 \mathrm{~mm}$ in mid-pedicle width dimension. Transverse pedicle angle was more at all levels and pedicles were sagittaly angulated in cephalad direction in comparison to other studies. Minimum value of interpedicular distance was at T5 (15.48 \pm 1.24$)$. Vertebral body width showed slight decrease from T1 to T4. The transverse process length was relatively constant between T2 to T10. The spinous process angle showed increasing trend from T1 to T6 and then gradually decreased to T12.

Conclusions: Most of the trends in changes of the parameters from T1 to T12 can be explained on the basis of local musculoskeletal anatomy and biomechanical stresses. The smallest diameter screw and shortest available screw for adults may not be safe in majority of the Indian population in mid-thoracic region. The results of the present study can help in designing implants and instrumentations; understanding spine pathologies; and management of spinal disorders in this part of the world.

Key Words: Anatomy, Morphometry, Thoracic spine, Pedicle, Indian

Received Sep 7, 2010; 1st Revised Nov 19, 2010; Accepted Nov 19, 2010

Corresponding author: Roop Singh, MD

Department of Orthopaedic Surgery, 52/9-J, Medical Enclave, PGIMS, Rohtak-124001, Haryana, India

Tel: +91-1262-213171, Fax: +91-1262-211301, E-mail: drroopsingh@rediffmail.com 


\section{Introduction}

Vertebral column comprising spine and spinal cord is one of the most complex structures of human body. In recent years there have been considerable developments in instrumentation designed to stabilize and correct the thoracic and lumbar spine [1]. Posterior fixation of the thoracic spine with rods, hooks, and wires has been used successfully to correct deformity and achieve stability in patients who have scoliosis, traumatic injury, or vertebral collapse secondary to infection [2]. Transpedicular screw fixation although gives rigid segmental fixation but there are concerns regarding this mode of fixation in the upper thoracic spine. There is associated potential risk of neurovascular injury in addition to the fractures of the pedicles [2-9]. Devices employing pedicular screwing consist of plates or rods, however in view of the wide variety and complexity of spinal instrumentation using pedicular screwing the configuration needs to be optimized [1].

Except for the two previous studies on morphometry of thoracic vertebrae, majority of studies mainly focused on pedicle diameters and their angulations [10,11]. The vertebral body, spinous process and transverse process were not studied or only little importance was given to them [1-9,1222]. Taking into account the complex nature of thoracic spine, the present study had given importance to the morphometry of vertebral body, spinous process and transverse process in addition to pedicles. Morphometric measurements of a particular geographical area will help in proper implant selection during spinal surgeries; designing of best suited implant; understanding the biomechanics and pathoanatomy of the spine; precise clinical diagnosis and management for the population under consideration. The parameters measured in the present study were selected considering the growing interest in the thoracic spine instrumentation and for better understanding of thoracic spine structure in Indian population.

The present study was conducted to collect a base line morphometric data of the thoracic spine in Indian population; to analyze the data thus collected in reference to the musculoskeletal anatomy and biomechanics of the spine; implants and instrumentations; and to suggest the requisite modification in spinal surgery instrumentations.

\section{Materials and Methods}

The study was conducted on 100 vertebral columns obtained from preserved sets of bones of individual dead bodies received at our institution. Mean age of cadavers was 52.8 years (range, 22 to 70 years). Vertebral columns with any spinal deformity, tumor, and fracture spine were excluded. The following measurements were done directly. Digital vernier caliper (resolution $0.1 \mathrm{~mm}$ ) was used for linear measurements and goniometer (resolution $1^{\circ}$ ) for angular measurements. Anatomy in all specimens was assessed by one researcher (CSVP) to ensue consistency. Each parameter was measured thrice and their averages were calculated. The data of each parameter was compared between right and left pedicles; right and left transverse processes; and male and female vertebrae at every level using independent t-test to assess statistically significant difference $(p<0.05)$.

\section{Following parameters were measured}

Parameters measured are shown in Fig. 1.

- Mid-pedicle width (MPW): The outer cortical transverse distance of the mid pedicle.

- Pedicle height (PH): The superior inferior outer cortical width of the pedicle measured at two sites namely mid pedicle (MPH) and at root of the pedicle (RPH) (junction of pedicle with the vertebral body).

- Minimal pedicle width (MIPW): After measuring pedicle width and height in transverse and vertical axis respectively the MIPW was measured by turning the vernier caliper until the diameter reading was the smallest.

- Pedicle length (PL): Distance form the posterior cortex of pedicle to the junction of pedicle with vertebral body in line with the axis of pedicle.

- Pedicle angle (PA): It is the angulation of pedicle both in sagittal and transverse plane (TPA).

- Chord length (CL): Measured from the posterior cortical entry point of the pedicle to the anterior vertebral cortex along the axis of the pedicle.

- Pedicle entrance point (PEP): The centre of pedicle in horizontal and vertical axis was determined visually and the PEP was the point of intersection of both axes.

- Canal dimension (CD): CDs were measured both in anteroposterior (APD) and interpedicular distance (IPD). 
- Vertebral body height (VBH): Distance between superior and inferior end plates was measured both anteriorly (VBHa) and posteriorly (VBHp).

- Vertebral body width (VBW): The width of vertebral body at superior end plate (VBWs), middle (VBWm) and inferior end plate (VBWi) was measured.

- Length of transverse process: Measured from base to tip of the transverse process.

- Width of transverse process at the base (WTPB): Distance between superior and inferior borders of the transverse process at base.

- Spinous process angle (SPRA): Angulation of the spinous process in the sagittal plane.

\section{Results}

Eighty-one vertebral columns belonged to male and 19 to female cadavers. We could not find any significant differences between right and left pedicles and right and left transverse processes in all the parameters measured. Therefore, the data was pooled and analyzed together in the present study.

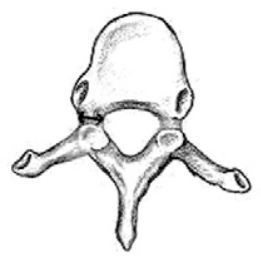

MPW
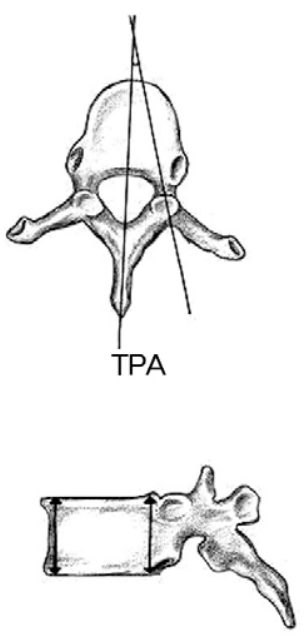

VBH

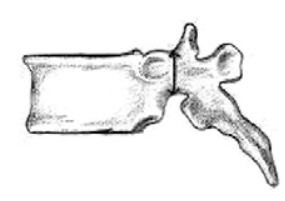

$\mathrm{PH}$

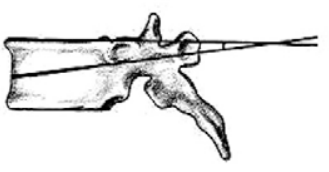

SPA

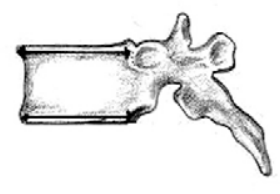

VBW

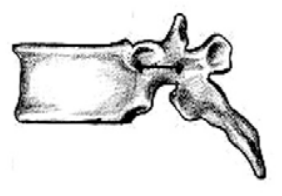

PL

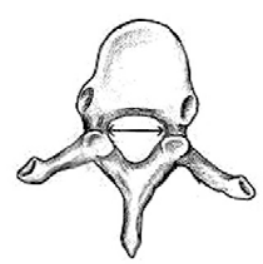

IPD

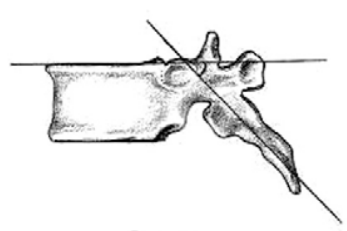

SPRA
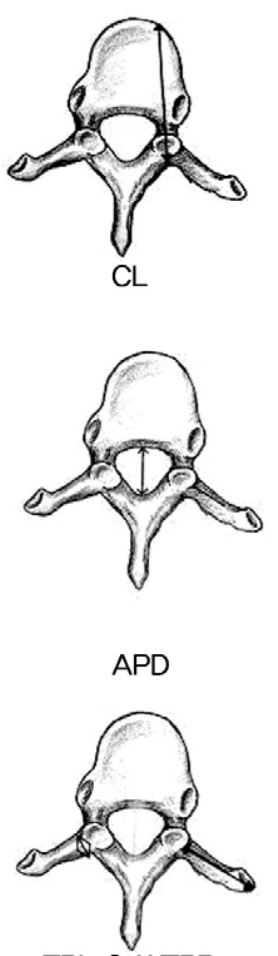

TPL \& WTPB

Fig. 1. Photographic representation of the parameters measured. MPW: Mid-pedicle width, PH: Pedicle height, PL: Pedicle length, CL: Chord length, PL: Pedicle length, TPA: Transverse pedicle angle, SPA: Sagittal pedicle angle, IPD: Interpedicular distance, APD: Anteroposterior distance of vertebral canal, VBH: Vertebral body height, VBW: Vertebral body width, SPRA: Spinous process angle, TPL: Transverse process length, WTPB: Width of transverse process base. 
and $6.88 \mathrm{~mm}$ for female vertebrae (Table 1). The minimum value was observed at T5 with the mean of $4.04 \mathrm{~mm}$ for whole series, $4.36 \mathrm{~mm}$ for male vertebrae and $3.61 \mathrm{~mm}$ for female vertebrae. The MIPW was smaller than MPW at all levels in the whole series. The PL had maximum mean value of $7.27 \mathrm{~mm}$ at T12 level in whole series and $7.22 \mathrm{~mm}$ and $7.58 \mathrm{~mm}$ for male and female specimens, respectively at the same level (Table 1). The minimum value was at the level of T6 in whole series with the mean of $6.48 \mathrm{~mm}$ and $6.45 \mathrm{~mm}$ for male vertebrae at the same level. Female vertebrae had $6.45 \mathrm{~mm}$ as minimum mean value at T3 level. The minimum CL was observed at $\mathrm{T} 1$ with the mean of 24.6 $\mathrm{mm}$ for whole series, $24.69 \mathrm{~mm}$ for male vertebrae and $24.22 \mathrm{~mm}$ for female vertebrae (Table 2). The CL gradually increased to a maximum value at $\mathrm{T} 11$ with the mean of 35.6 $\mathrm{mm}$ for whole series and $36.34 \mathrm{~mm}$ for male vertebrae. The female vertebrae had maximum value at $\mathrm{T} 10$ with a mean of $33.27 \mathrm{~mm}$. The CL after attaining maximum value decreased at T12 level. The chord lengths of male vertebrae were more than female vertebrae at all levels. The maximum TPA was at T1 level with the mean values of $31.8^{\circ}$ for whole series, $32.26^{\circ}$ for male vertebrae and $30.24^{\circ}$ for female vertebrae (Table 2). The TPA gradually decreased to attain minimum value at $\mathrm{T} 12$ level with the mean values of $-10.01^{\circ}$ for whole series, $-10.03^{\circ}$ for male vertebrae and $10^{\circ}$ for female vertebrae. The sagittal PA had a plateau between $\mathrm{T} 1$ to $\mathrm{T} 9$ vertebrae with values ranging between $17.6^{\circ}$ and $14.80^{\circ}$, and gradually decreased to minimum value at T12 vertebrae with the mean of $3.92^{\circ}$ for whole series, $4.07^{\circ}$ for male vertebrae and $3.31^{\circ}$ for female vertebrae (Table 2).

The PEP was observed at intersection of line along middle of superior facet and line along middle 1/3rd segment of transverse process in $\mathrm{T} 1$ to $\mathrm{T} 3$ vertebrae. Whereas, it was observed at intersection of line along middle of superior facet and line along upper 3rd segment of transverse process in $\mathrm{T} 4$ to $\mathrm{T} 12$ vertebrae. The PEP was found same for both male and female specimens. The maximum IPD was found at T1 with the mean of $19.76 \mathrm{~mm}$ for whole series, $19.78 \mathrm{~mm}$ for male vertebrae and $19.70 \mathrm{~mm}$ for female vertebrae (Table 2). The IPD gradually decreased to minimum value at T5 with mean of $15.48 \mathrm{~mm}$ for whole series and then increased till T12 region with mean of 18.96 $\mathrm{mm}$ for whole series. The IPD of female specimens were slightly more than male specimens except at $\mathrm{T} 1, \mathrm{~T} 2$ and $\mathrm{T} 7$ vertebrae. The APD had relatively stable values between T1 to $\mathrm{T} 12$. The minimum mean value was observed at $\mathrm{T} 2$ for whole series $(13.80 \mathrm{~mm})$ and female vertebrae $(13.85 \mathrm{~mm})$ (Table 2). The male vertebrae had minimum mean value at $\mathrm{T} 1(13.76 \mathrm{~mm})$. The maximum value was at $\mathrm{T} 12$ level with the mean of $15.87 \mathrm{~mm}$ for whole series, $15.79 \mathrm{~mm}$ for male vertebrae and $16.23 \mathrm{~mm}$ for female vertebrae. The anteroposterior distance of vertebral canal was found more in female vertebrae than in male vertebrae at all levels.

The minimum VBHa body was observed at $\mathrm{T} 1$ with the mean of $14.94 \mathrm{~mm}$ for whole series, $15.13 \mathrm{~mm}$ for male vertebrae, and $14.12 \mathrm{~mm}$ for female vertebrae (Table 3). The height gradually increased to a maximum value at $\mathrm{T} 12$ level with the mean of $22.21 \mathrm{~mm}$ for whole series, 22.30 $\mathrm{mm}$ for male vertebrae and $21.83 \mathrm{~mm}$ for female vertebrae. The VBHp had a minimum value at $\mathrm{T} 1$ region with the mean of $15.86 \mathrm{~mm}$ for whole series, $16.14 \mathrm{~mm}$ for male vertebrae and $14.63 \mathrm{~mm}$ for female vertebrae (Table 3). The height increased gradually and reached maximum at T12 region with the mean of $29.65 \mathrm{~mm}$ for whole series, 29.85 $\mathrm{mm}$ for male vertebrae and $29.35 \mathrm{~mm}$ for female vertebrae.

There was slight decrease in VBW from $\mathrm{T} 1$ to $\mathrm{T} 4$ and VBWs had minimum value at T4 level with the mean of $24.75 \mathrm{~mm}$ for whole series, $25.16 \mathrm{~mm}$ for male vertebrae and $23.03 \mathrm{~mm}$ for female vertebrae (Table 3). From T4 it increased to reach maximum value at $\mathrm{T} 12$ with the mean of $36.5 \mathrm{~mm}$ for whole series, $37.1 \mathrm{~mm}$ for male vertebrae and $33.99 \mathrm{~mm}$ for female vertebrae. The male vertebrae were wider at superior end plate as compared to female vertebrae. The VBWm had minimum value at T4 level with the mean of $23.74 \mathrm{~mm}$ for whole series, $24.02 \mathrm{~mm}$ for male vertebrae, and $22.57 \mathrm{~mm}$ for female vertebrae (Table 3). From T4 it increased to reach maximum value at $\mathrm{T} 12$ with the mean of $34.31 \mathrm{~mm}$ for whole series, $34.67 \mathrm{~mm}$ for male vertebrae and $32.91 \mathrm{~mm}$ for female vertebrae. Male vertebrae were found to be wider than female vertebrae at mid-vertebral level. The VBWi decreased from T1 (mean of $29.04 \mathrm{~mm}$ in whole series) to reach the minimum value at $\mathrm{T} 3$ level with the mean of $27.11 \mathrm{~mm}$ for whole series, 27.53 for male vertebrae and $25.35 \mathrm{~mm}$ for female vertebrae (Table 3). Then the width increased till T12 to reach maximum value with the mean of $39.49 \mathrm{~mm}$ for whole series, $39.89 \mathrm{~mm}$ for male vertebrae and $37.67 \mathrm{~mm}$ for female vertebrae. The VBWi was found more in male vertebrae compared to female vertebrae.

The transverse process length (TPL) increased from T1 (14.12 mm - whole series mean) and reached maximum value at T6 with mean of $19.41 \mathrm{~mm}$ for whole series, 19.51 $\mathrm{mm}$ for male vertebrae and $18.92 \mathrm{~mm}$ for female vertebrae 


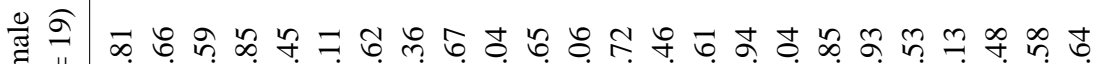

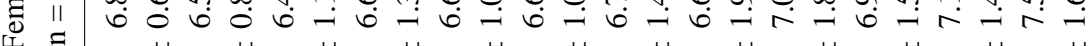

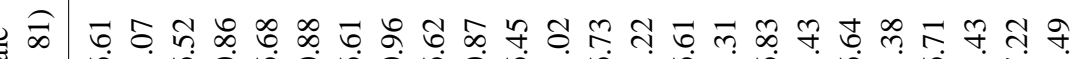

$\Xi \begin{array}{lllllllll}+1 & +1 & +1 & +1 & +1 & +1 & +1 & +1 & +1\end{array}$

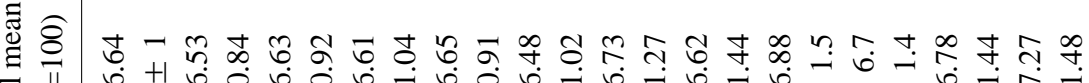

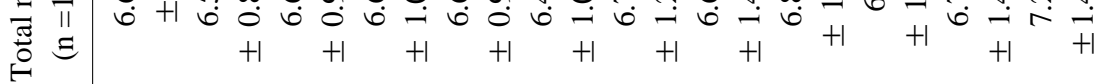
๖ $\curvearrowright$ 尺

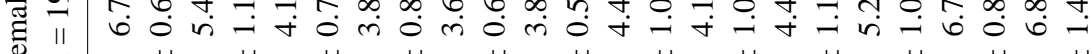

ㅇำ

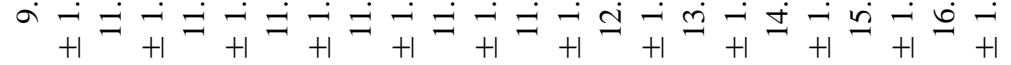
ฮี

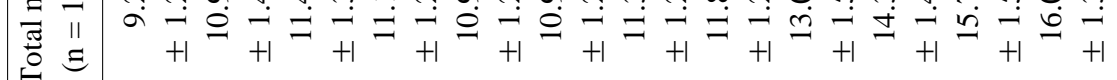

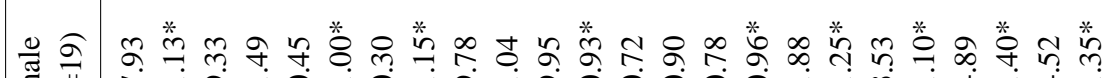

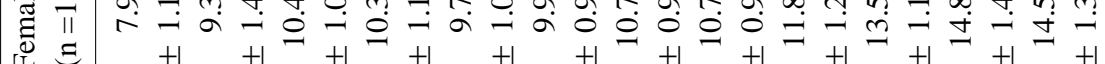

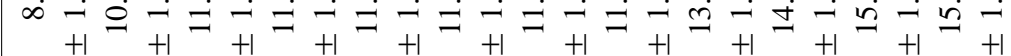

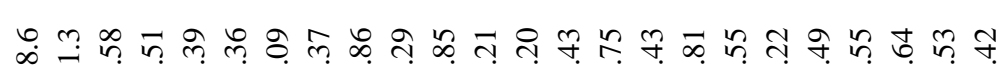

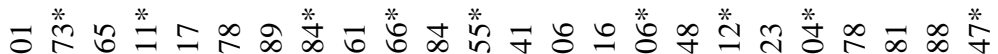

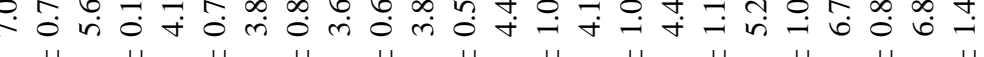
$\infty$ б

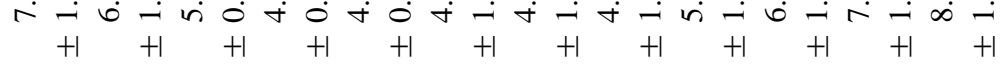

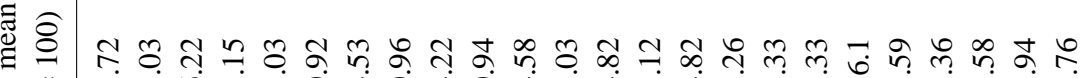

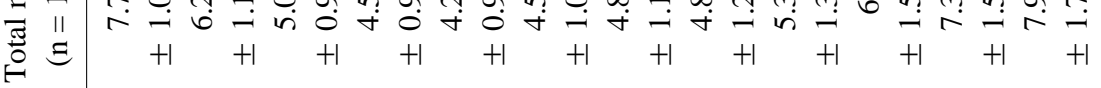




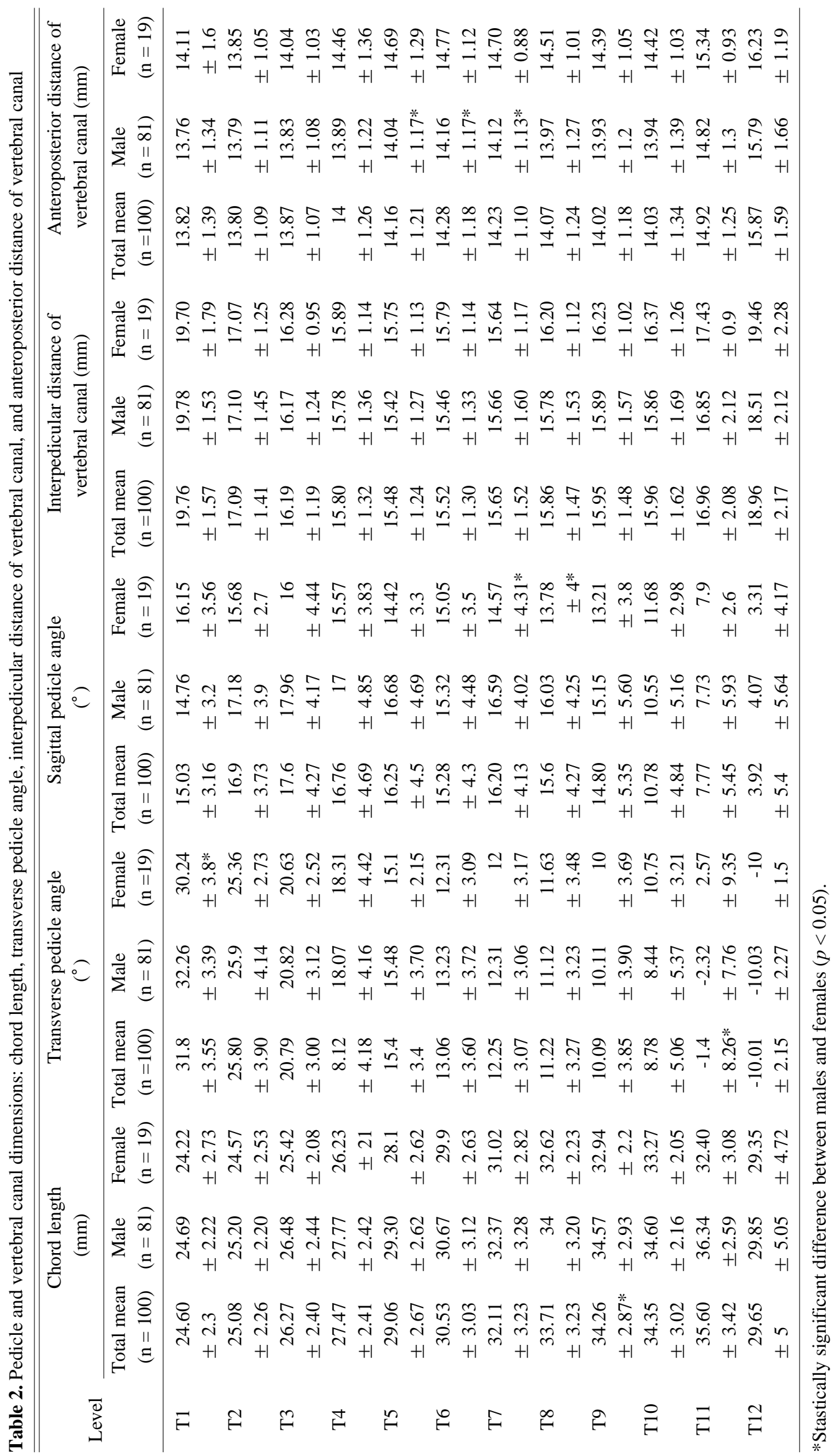




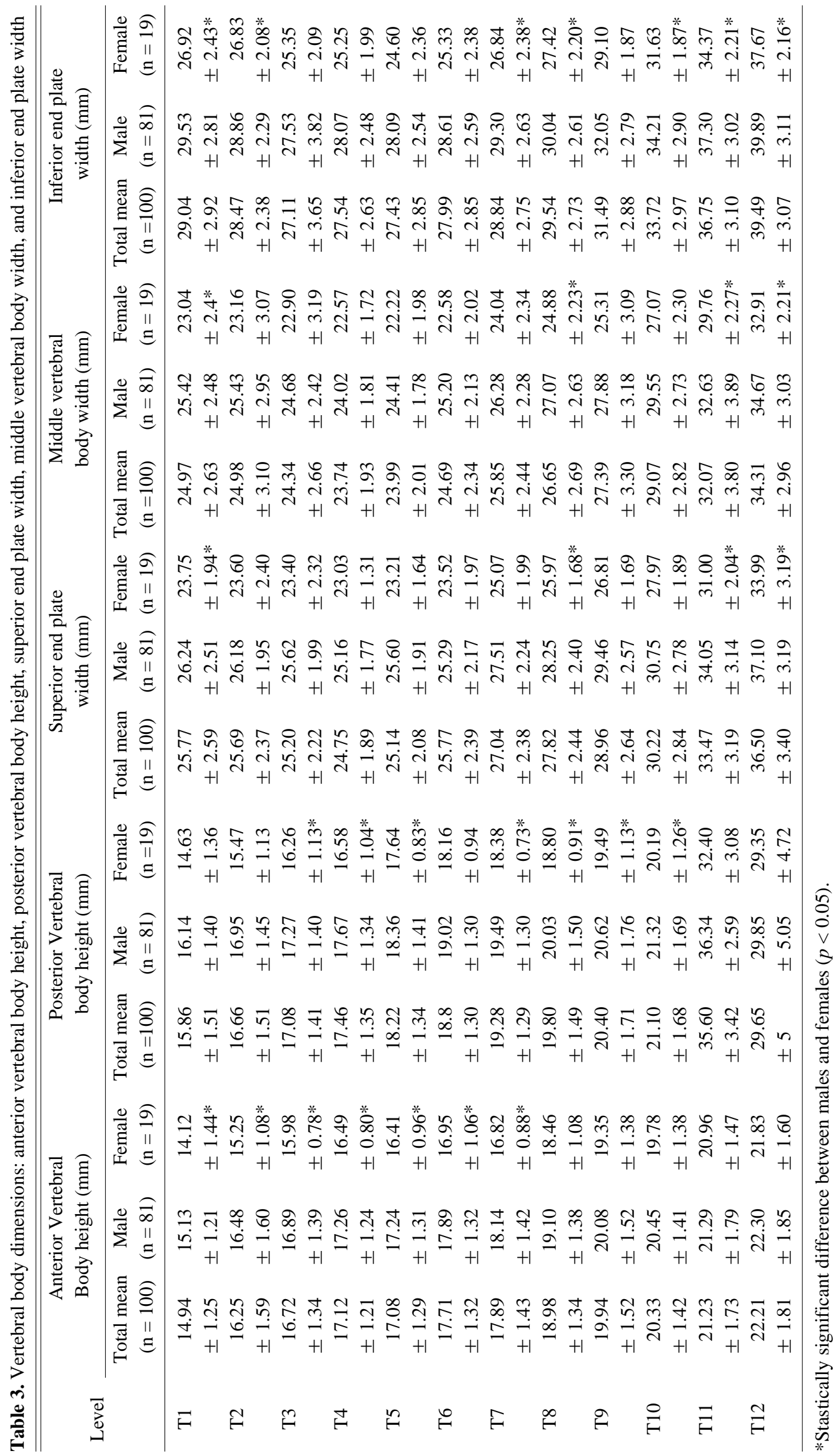


(Table 4). Then the length decreased gradually to reach minimum value at $\mathrm{T} 12$ with the mean of $8.93 \mathrm{~mm}$ for whole series, $10.35 \mathrm{~mm}$ for male vertebrae and $8.6 \mathrm{~mm}$ for female vertebrae. The WTPB was relatively stable between T1 to T12. The maximum value was found at T8 level with the mean of $11.7 \mathrm{~mm}$ for whole series, $11.81 \mathrm{~mm}$ for male vertebrae and $11.27 \mathrm{~mm}$ for female vertebrae (Table 4). The minimum value was at T12 with the mean of $10.13 \mathrm{~mm}$ for whole series, $10.35 \mathrm{~mm}$ for male vertebrae and $9.19 \mathrm{~mm}$ for female vertebrae. The SPRA increased from T1 (mean of $28.37^{\circ}$ in whole series) and reached maximum value at T6 level with the mean values of 58.91 degrees for whole series and $59.83^{\circ}$ for male vertebrae (Table 4). Female vertebrae attained maximum value at $\mathrm{T} 7$ with the mean of $55^{\circ}$. The angle then decreased gradually and reached minimum value at T12 level with the mean values of $13.15^{\circ}$ for whole series, $13.12^{\circ}$ for male vertebrae and $13.26^{\circ}$ for female vertebrae.

\section{Discussion}

The present study was undertaken to gain a detailed knowledge of the vertebral morphology of thoracic spine in India and the observations from the present study were compared with the previous published studies from India $[18,19,22]$, Asia [11,14,15,21], and western world $[10,12,13,16-20]$. It included more number of cadaveric specimens in comparison to other studies which included 640 cadaveric specimens. The previous studies done in India in this regard by Datir and Mitra [18] was based on 18 cadaveric specimens, by Chadha et al. [19] on 31 patients and recently published study by Acharya et al. [22] on 50 patients. All of these studies have focused primarily on pedicle morphometry and except for Datir and Mitra [18] two studies have only studied lower thoracic pedicles. Male to female ratio was $4.2: 1$ in the present study.

Pedicle is the strongest part of the vertebra and the pull out strength of the screw depends on the integrity of the pedicle. A good knowledge of the pedicle size is therefore essential for proper instrumentation. The MPW gradually decreased from T1 to T5 and started increasing from T6 to T12 in the present study. Similar trend was also seen in almost all studies reported in literature $[4,6,7,9,20]$. We got minimum mean value of $4.2 \mathrm{~mm}$ at T5. Vaccaro et al. [2], Datir and Mitra [18] and Zindrick et al. [7] also had minimum value at T5 level which were all around $4.5 \mathrm{~mm}$. Whereas Ugur et al. [6] and Ebraheim et al. [4] had mini- 
mum value at T4 level (Fig. 2). This trend of change in size of the pedicles may be due to transition from a more mobile cervicothoracic junction to relatively fixed mid-thoracic region and again to a mobile thoracolumbar junction putting differential stress on the facet joints and pedicles. In the present study, values of MPW less than $5 \mathrm{~mm}$ were observed for T4 to T8 similar to other studies reported in the literature [2,3] Whereas some other studies in the literature reported higher values at all levels and at no level the width was less than $5 \mathrm{~mm} \mathrm{[20]} 35 \%$ of all pedicles, $48 \%$ of those from T4 through $\mathrm{T} 8$ and $68 \%$ of those at T6, measured less than $5 \mathrm{~mm}$ in a study reported by Cinotti et al. [3] In another study by McLain et al. [17] 25\% of T1 pedicles, $17 \%$ of $\mathrm{T} 2$ pedicles, $42 \%$ of the $\mathrm{T} 3$ pedicles, $61 \%$ of $\mathrm{T} 4$ pedicles, $67 \%$ of $\mathrm{T} 5$ pedicles and $75 \%$ of $\mathrm{T} 6$ pedicles were too small to accept a $5.5 \mathrm{~mm}$ screw. In the present study, $35.5 \%$ of all the pedicles; $71 \%$ of T5 pedicles; $54.6 \%$ of all the female pedicles; and $94.4 \%$ of the T5 pedicles in females were smaller than $5 \mathrm{~mm}$ in MPW dimension. Thus, we agree with Datir and Mitra [18] that even a 4-mm screw should be used carefully at the mid-thoracic level; 5-mm screw seems to be safe at upper and lower levels of the thoracic spine. Tan et al. [11] also pointed that except for $\mathrm{T} 1$ and T10-T12, the pedicle width was not wide enough to accommodate a 5-mm transpedicular screw. Liau et al. [21] reported that the $67.8 \%$ male and $94.4 \%$ females had transverse outer pedicle diameter less than 5-mm at T4; and $62.2 \%$ males and $90.0 \%$ females at T5 level. We also agree with other studies that the pedicles between $\mathrm{T} 4$ and $\mathrm{T} 8$ should be measured on computed tomography scans before surgery, because they might not be suitable to instrumentation with pedicle screws due to their narrow width [2,3,6,21].

Islam et al. [23] emphasized most vertebrae have a real minimal diameter, which is the smallest diameter of the pedicle and they reported the ratio of vertical or transverse diameter to minimal diameter for each level to estimate real minimal diameter. The axis of minimal diameter which is the smallest is generally oblique and is different from the vertical and transverse axes, although it is sometimes superimposed on either [23]. At all levels the MIPW was almost $0.5 \mathrm{~mm}$ less than the transverse pedicle width in the present study (Table 1). The MIPW of T4-T6 levels in female cadavers were less than $4 \mathrm{~mm}$. This result again shows that even the smallest available pedicle screw diameter may be too large for mid thoracic segment. Considering the small size of pedicles in thoracic spine, some authors proposed extrapedicular fixation within the pedicle unit to avoid medial wall violation $[9,24]$.

In the present study the PH increased from $\mathrm{T} 1$ to $\mathrm{T} 3$ and

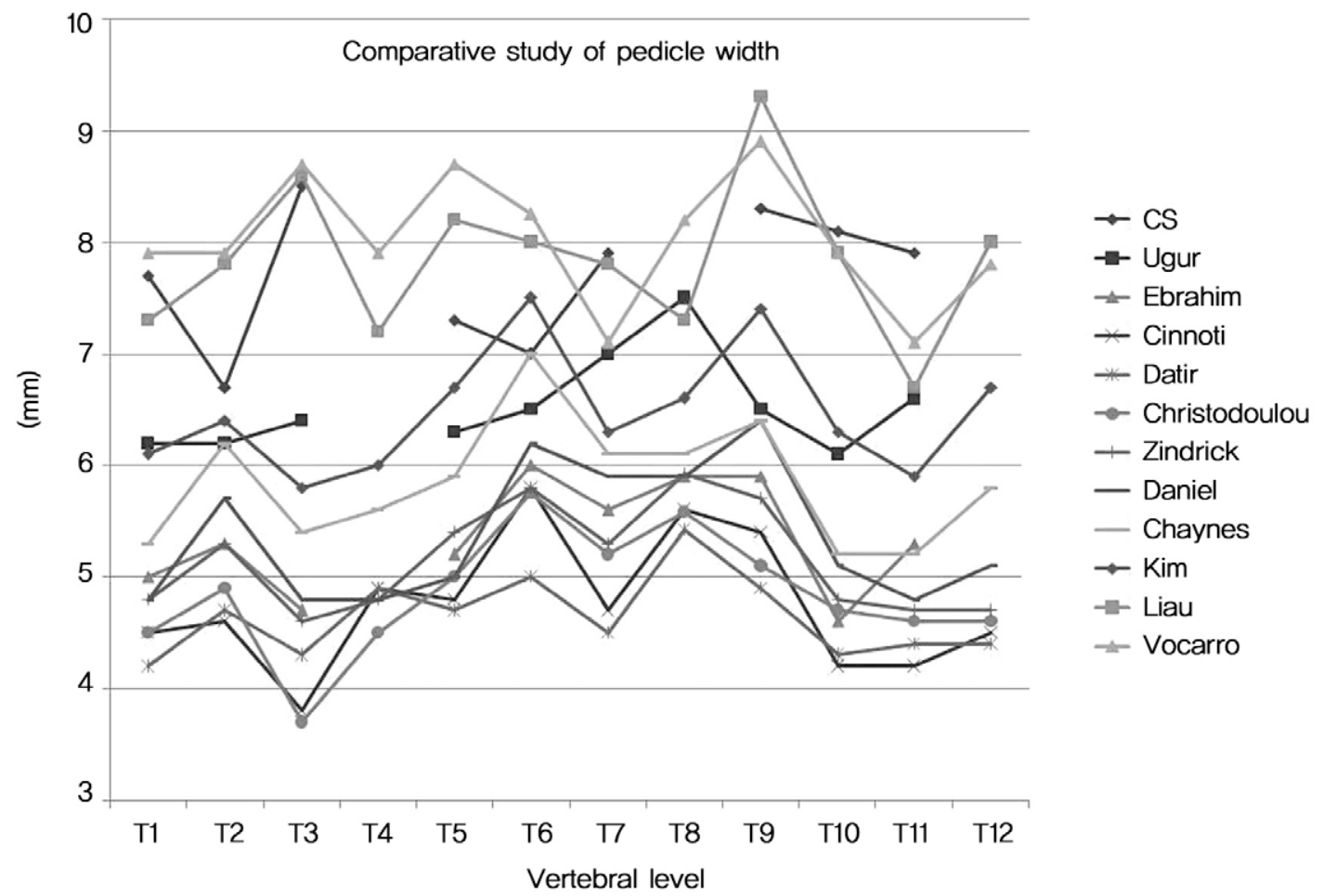

Fig. 2. Comparative study of pedicle width between current study (CS) and other studies $[1-4,6,7,9,15,18,20,21]$. 
there was a slight fall from T4 to T6 and then it gradually increased till T12 level. Similar trend was also seen in studies of Datir and Mitra [18] and Zindrick et al. [7]; but not in the study by Christodoulou et al. [20] which showed gradual increase from T1 to T12. The MPH of the present study was lower than the other studies $[7,18,20]$ except for Vaccaro et al. [2] whose PH dimensions were lower than present study. Comparison of pedicle width and $\mathrm{PH}$ explains for the oval shape of pedicle cross section except for 1st pedicle which is cylindrical with more or less equal width and height $(7.7 \mathrm{~mm}$ and $8.6 \mathrm{~mm})$. Since the $\mathrm{PH}$ is more than pedicle width at all levels, it does not limit the size of the screw to be used.

The PL in the present study was found to be stable around $6.5 \mathrm{~mm}$ to $7.2 \mathrm{~mm}$ at all levels. PL in the studies by Husted et al. [9], Ebraheim et al. [4] and Vaccaro et al. [2] based on western population were higher $(9-27.2 \mathrm{~mm})$ compared to the present study based on Indian population. The CL increased gradually from $\mathrm{T} 1$ to $\mathrm{T} 11$ and decreased at T12 level in the present study which is consistent with the literature (Fig. 3). Compared to the two other studies from India, the values in the present study were similar to that of Datir and Mitra [18] except for T12 vertebra which had smaller CL. This is explained by more lateral angulation of T12 pedicle in the present study. Chadha et al. [19] reported higher values at $\mathrm{T} 9$ and $\mathrm{T} 10$ levels, but comparable values at T11 and T12 levels. The CL reported in other studies based on western population was higher at all levels compared to studies based on Indian population [2,7,20]. Based on the present study $25 \mathrm{~mm}$ length screws would be appropriate for upper thoracic vertebrae except $\mathrm{T} 1$ and $\mathrm{T} 2$ where even $25 \mathrm{~mm}$ screws may breach anterior vertebral cortex. In lower thoracic vertebrae $30 \mathrm{~mm}$ screw length would be appropriate except for T12 where it may end up longer in most individuals.

Transverse PA was more from $\mathrm{T} 1$ to $\mathrm{T} 10$ in the present study compared to other studies from white population (Fig. 4). The pedicles were angulated more medially initially and gradually came to neutral position around T10/T11 level and it faced more laterally at T12 region in the present study. In another Indian study by Datir and Mitra [18] the pedicles reached neutral position rather earlier and at no levels the pedicle were facing laterally. In a study by Chadha et al. [19] the pedicles were facing laterally at lower end

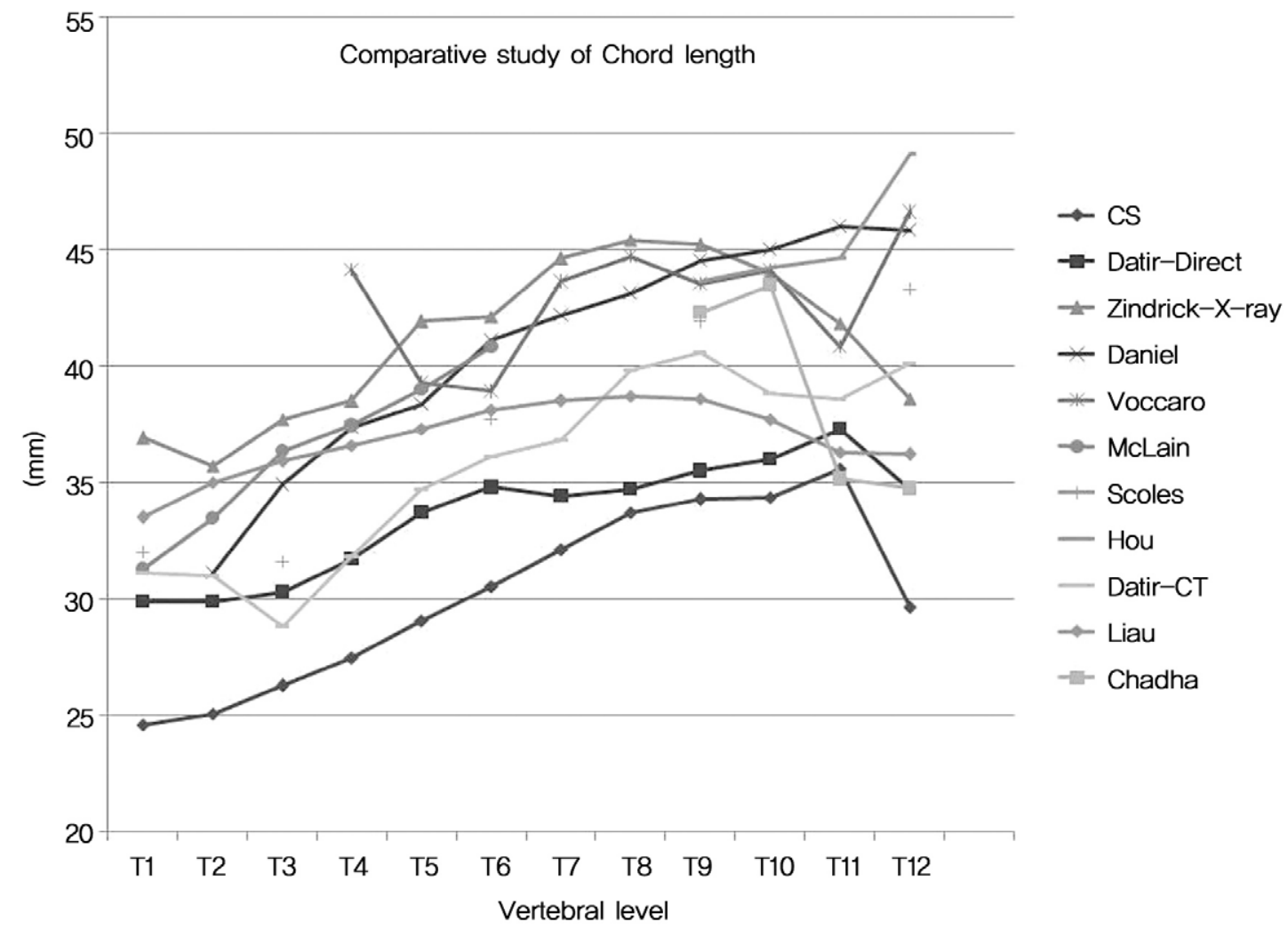

Fig. 3. Comparative study of chord length between current study (CS) and other studies $[2,7,9,13,14,17-19,21]$. CT: Computed tomography. 
but less compared to our study. Recently published study by Acharya et al also showed in lower thoracic spine pedicles faced more laterally [22]. Going for pedicle screw instrumentation on the basis of other study groups would have lead to risking cord and neural structures. Because of the more lateral angulation of $\mathrm{T} 12$ pedicle the $\mathrm{CL}$ of the T12 vertebra was also less as compared to other lower thoracic vertebrae.

The pedicles were sagittaly angulated in cephalad direction with a narrow range between T1-T9 $\left(15-17.6^{\circ}\right)$ in the present study. Then the cephalad angle decreased from T10T12 with more than $50 \%$ of T12 having sagittal angle of $0^{\circ}$. Compared to Datir and Mitra [18] the present study group had more cephalad angulation but the trend being the same. Zindrick et al. [7] had got similar values as in the present study but the lower three thoracic vertebrae angled more cephalad as compared to the present study. The present study group had maximum sagittal angle at $\mathrm{T} 3$ level $\left(17.6^{\circ}\right)$ whereas Zindrick et al. [7] and Datir and Mitra [18] had maximum value at $\mathrm{T} 2$ level $\left(17.5^{\circ}\right.$ and $11.8^{\circ}$ respectively).

Different studies differ in defining the entry point for pedicles and they differ at each segment of vertebrae. Com- paring our results with other Indian study by Datir and Mitra [18] the horizontal axis of entry point was same but the vertical axis reference point was different. The entry point for western population based on studies of Vaccaro et al. [2] and Cinotti et al. [3] differed from that of Indian population.

In the present study, IPD decreased from T1 to T5 with mean value of $15.48 \pm 1.24 \mathrm{~mm}$ at $\mathrm{T} 5$ and then gradually increased from T6 to T12 with mean value of $18.96 \pm 2.17$ $\mathrm{mm}$ at T12. The similar trend was observed by Ugur et al. [6], Panjabi et al. [10], Scoles et al. [13], Berry et al. [12], Tan et al. [11], and McCormack et al. [16]. However, the studies by Datir and Mitra [18] and Chaynes et al. [1] showed higher values at all levels and with uniformly increasing trend from T1 to 12 (Fig. 5). The mid-thoracic region is important because it is critical vascular zone for the spinal cord. It has the narrowest opening, and blood supply to the spinal cord is least perfuse [25]. Surgical situation in this site is further compounded by the fact that this is the area of least pedicular width also. Any medial misdirection of the pedicle screw during surgery is going to cause nerve root damage, dural tear, or spinal cord damage. The APD

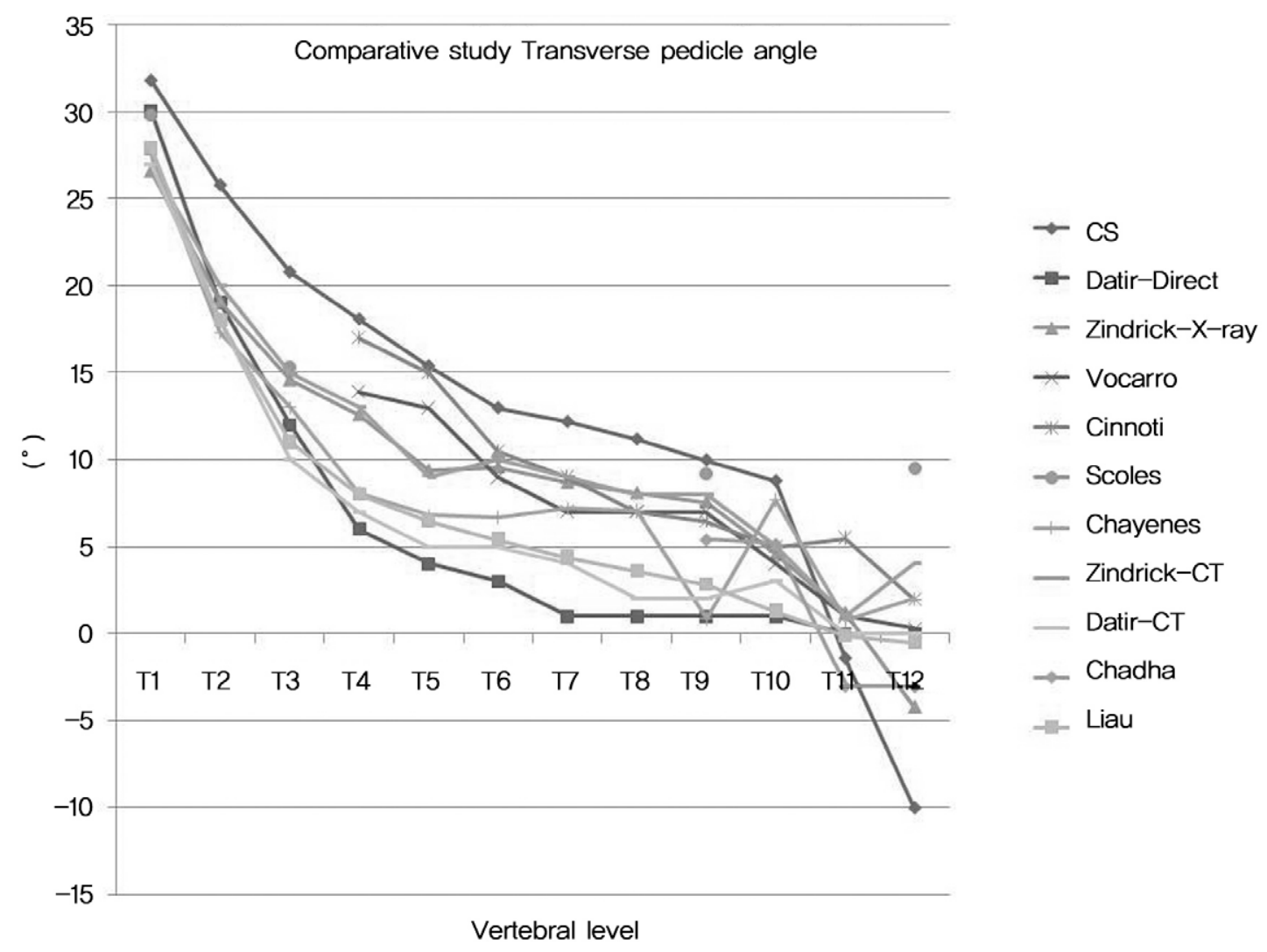

Fig. 4. Comparative study of transverse pedicle angle between current study (CS) and other studies $[1,2,3,7,13,18,19,21]$. CT: Computed tomography. 
was found relatively stable between $\mathrm{T} 1(13.82 \mathrm{~mm})$ to $\mathrm{T} 12$ $(15.87 \mathrm{~mm})$. Tan et al. [11] also reported similar findings with mean values of $11.6 \mathrm{~mm}$ at $\mathrm{T} 1$ to $12.4 \mathrm{~mm}$ at $\mathrm{T} 12$, but all levels the canal dimensions were wider in the present study compared to than that reported in Chinese Singaporeans. The APD values in female vertebrae were higher compared to male vertebrae at all levels and this difference was statically significant at T5, T6 and T7 levels $(p<0.05)$. The interpedicular distance was also found to be higher in females in all levels except at $\mathrm{T} 1, \mathrm{~T} 2$ and $\mathrm{T} 7$ vertebrae. Thus, it was observed that the vertebral canal in female vertebrae was wider than male vertebrae in the present study group. This was in contradiction to other dimensions where values in male vertebrae were found higher than female vertebrae values.

The anterior and posterior VBHs were found to have similar trends with values gradually increasing from $\mathrm{T} 1$ to $\mathrm{T} 12$. The values from male vertebrae were higher at all levels as compared to values from female vertebrae. The VBHa was found to be less as compared to the VBHp at all levels. This observation explains for the normal physiological kyphosis present in the thoracic region. Vertebral height was more in the present study from that reported by Tan et al. [11].
VBHa was more on an average by $2.6 \mathrm{~mm}$ (range, 1.8 to 3.7 $\mathrm{mm}$ ) and VBHp by $1.9 \mathrm{~mm}$ (range, 1.3 to $2.4 \mathrm{~mm}$ ) in the present study compared to them.

The VBWs and VBWm had slight decrease from T1 to T4 and started increasing gradually till twelfth vertebrae. The VBWi decreased from T1 to T3 and started increasing till T12 level. Similar trends were also observed by Tan et al. [11]. However; VBWs was more on an average by 1.8 $\mathrm{mm}$ (range, 1 to $2.4 \mathrm{~mm}$ ) and VBWi width by $2.3 \mathrm{~mm}$ (range, 1.4 to $3.4 \mathrm{~mm}$ ) in the present study. The values from male vertebrae were more as compared to values from female vertebrae at all levels. As we go down the thoracic spine the vertebral body size increases. In other words as the load on vertebra increases the vertebral body size, which is mainly involved in transfer of weight, also increases.

The transverse process in thoracic region has three significances. It is the site of articulation with the ribs and gives attachments to various muscles. Thirdly, it is one of the sites of hook implantation during deformity correction surgeries. With this in mind we measured the length and width at root of transverse process which had never been attempted by any other studies in thoracic region. The TPL was relatively constant between $\mathrm{T} 2$ to $\mathrm{T} 10$ with the mean range of

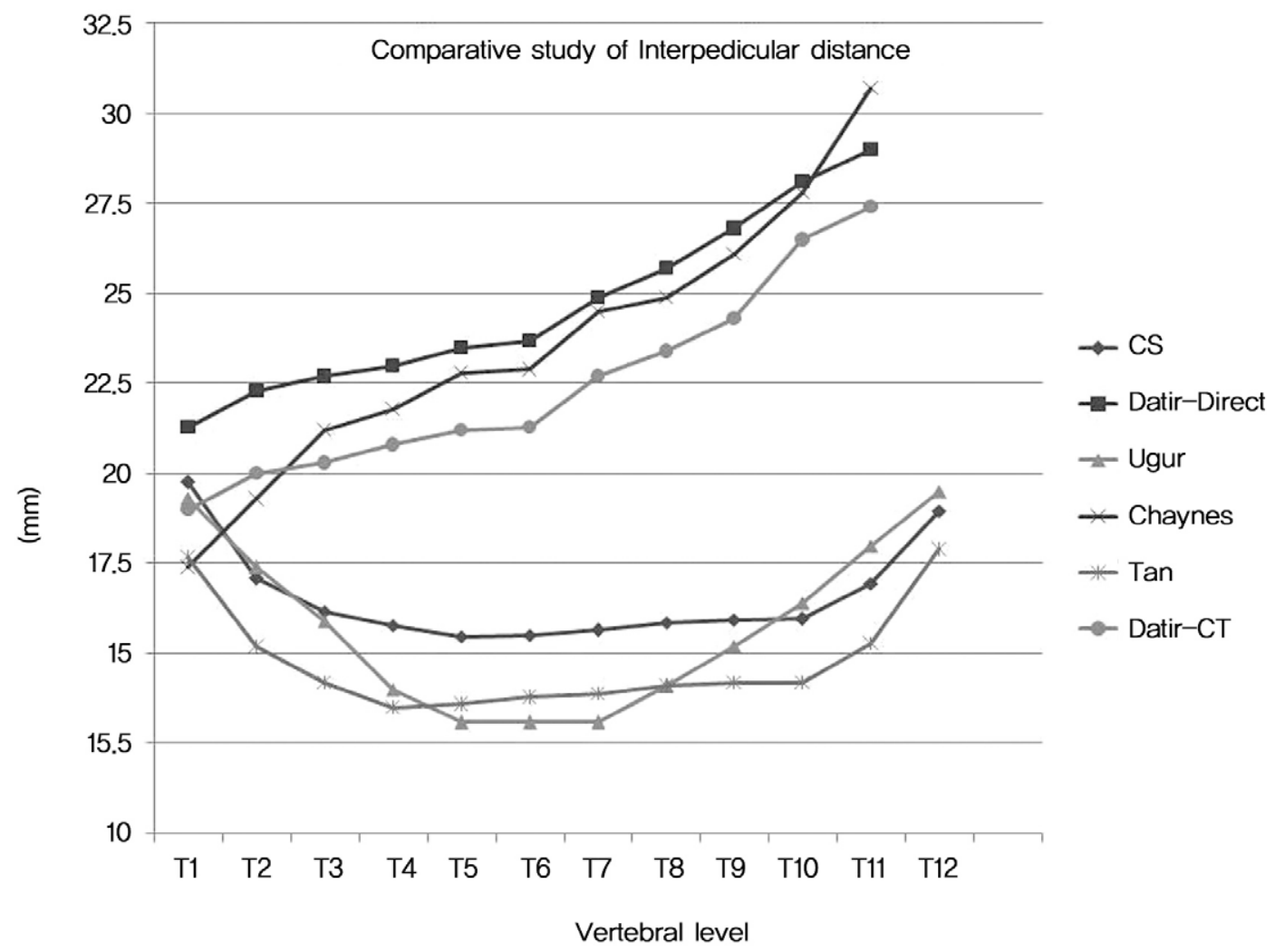

Fig. 5. Comparative study of interpedicular distance between current study (CS) and other studies $[1,6,11,18]$. 
$17.32 \mathrm{~mm}$ at $\mathrm{T} 2$ to $16.23 \mathrm{~mm}$ at $\mathrm{T} 10$. The $\mathrm{T} 11$ and $\mathrm{T} 12$ transverse processes were smaller with mean values of 12.4 $\mathrm{mm}$ and $8.9 \mathrm{~mm}$ respectively. This probably may be explained on the basis of muscular attachments and size of articulating ribs. More muscles are attached to the upper thoracic transverse processes (Semispinalis and Longissimus group attaches only to upper thoracic transverse process; Levatores Costaram to T7 to T11 transverse processes) compared to the lower two transverse process [26]. The last two ribs are smaller in size and do not attach anteriorly (floating ribs). The lengths of transverse processes were almost equal in both male and female specimens. The WTPB were within narrow range from $\mathrm{T} 1$ to $\mathrm{T} 12$. The maximum width was found at the level of T8 (mean, 11.7 $\mathrm{mm}$ ) and narrowest at T12 (mean, $10.13 \mathrm{~mm}$ ). The transverse process width values may help to design hooks as per Indian population.

The angle of orientation of spinous process to the vertebral body was studied as the SPRA was having wide variations in thoracic region. Our study analyzed the variations of SPRA at different levels and its relations with the movement occurring at the vertebral column. The SPRA in the present study showed increasing trend from $\mathrm{T} 1\left(28.3^{\circ}\right)$ to $\mathrm{T} 6\left(59.8^{\circ}\right)$ and then gradually decreased to $\mathrm{T} 12\left(13.12^{\circ}\right)$. The thoracic spine is a complex structure with two transitional zones at its upper and lower ends. The extension and flexion movements are more in lower thoracic segment compared to the middle and upper thoracic segment which are relatively rigid [27]. The spinous process in the upper and middle thoracic segment overlaps each other like slates on a roof [27]. This overlapping of spinous process with relatively short interspinous ligaments in between them may also be a limiting factor for flexion and extension in the upper and middle thoracic segment. Relatively widely placed spinous processes at lower ends of thoracic spine may be a contributing factor for more movements occurring at this region as compared to the upper and middle thoracic segment. The direction of pull by latissimus dorsi muscle and lower fibers of trapezius which have their attachments to the spinous processes of lower half of the thoracic vertebrae may also be a reason for decrease in SPRA from T6 to T12 [26].

\section{Analysis of the data in reference to spine instru- mentation available}

The present study gathered morphological data on tho- racic spines in Indian population that should serve as useful reference for spinal surgery instrumentation. The available sizes of pedicle screw implants for adults ranges from diameter of 4-mm to 9-mm and length ranging from $25 \mathrm{~mm}$ to 45 $\mathrm{mm}$. Going by the data collected by the present study the smallest screw $(4 \mathrm{~mm} \times 25 \mathrm{~mm})$ available for adult instrumentation may be bigger for $35.5 \%$ of all the pedicles; $71 \%$ of T5 pedicles; $54.6 \%$ of all the female pedicles; and $94.4 \%$ of the T5 pedicles in females in the Indian population. Systems relying only on pedicle screws may not be safe in upper and mid-thoracic region from both biomechanical and clinical point of view. As per biomechanics the smallest and shortest screws if used would render the construct weak which may fail. As per clinical point of view screws may breach both the pedicles and the anterior vertebral cortex endangering neurovascular structures.

\section{Recommendation for modification in spinal surgery instrumentations in Indian population}

(1) Modification of spinal implants (screw/hooks/cages) after modeling of thoracic vertebrae in accordance with the morphometric data obtained in the present study.

(2) Fabrication of pedicle screws in such a way to increase strength and to avoid fatigue failure by utilizing advanced engineering techniques.

(3) Preoperatively determining the size of pedicles using imaging techniques.

(4) Use of advanced surgical techniques like computer and spinal navigation assisted spinal surgery instrumentation.

(5) Instrumentation systems based on hooks for pedicles and transverse process for upper thoracic vertebrae and pedicle screws for lower thoracic vertebrae may be used for spinal fixation and deformity corrections.

\section{Conclusions}

Most of the changes in the parameters from T1 to T12 can be explained on the basis of local musculoskeletal anatomy and biomechanical stresses. In contradiction to other vertebral dimensions where values in males were found to be higher than females; vertebral canal dimensions in females except for IPD at T1 and T2 were wider than males in Indian population. The smallest diameter screw and shortest available screw for adults are not safe in major- 
ity of the Indian population in mid-thoracic region. The pedicle are directed more medially from $\mathrm{T} 1$ to $\mathrm{T} 10$ and also more laterally angulated at lower two thoracic levels, the significant fact to be considered while placing pedicle screws The results of the present study can help in designing implants and instrumentations; understanding spine pathologies; and management of spinal disorder in this part of the world.

\section{REFERENCES}

1. Chaynes P, Sol JC, Vaysse P, Bécue J, Lagarrigue J. Vertebral pedicle anatomy in relation to pedicle screw fixation: a cadaver study. Surg Radiol Anat 2001;23:85-90.

2. Vaccaro AR, Rizzolo SJ, Allardyce TJ, et al. Placement of pedicle screws in the thoracic spine. Part I: morphometric analysis of the thoracic vertebrae. J Bone Joint Surg Am 1995;77:1193-9.

3. Cinotti G, Gumina S, Ripani M, Postacchini F. Pedicle instrumentation in the thoracic spine: a morphometric and cadaveric study for placement of screws. Spine (Phila Pa 1976) 1999;24:114-9.

4. Ebraheim NA, Xu R, Ahmad M, Yeasting RA. Projection of the thoracic pedicle and its morphometric analysis. Spine (Phila Pa 1976) 1997;22:233-8.

5. Panjabi MM, O’ Holleran JD, Crisco JJ 3rd, Kothe R. Complexity of the thoracic spine pedicle anatomy. Eur Spine J 1997;6:19-24.

6. Ugur HC, Attar A, Uz A, Tekdemir I, Egemen N, Genç Y. Thoracic pedicle: surgical anatomic evaluation and relations. J Spinal Disord 2001;14:39-45.

7. Zindrick MR, Wiltse LL, Doornik A, et al. Analysis of the morphometric characteristics of the thoracic and lumbar pedicles. Spine (Phila Pa 1976) 1987;12:160-6.

8. Zindrick MR, Knight GW, Sartori MJ, Carnevale TJ, Patwardhan AG, Lorenz MA. Pedicle morphology of the immature thoracolumbar spine. Spine (Phila Pa 1976) 2000;25:2726-35.

9. Husted DS, Haims AH, Fairchild TA, Kershaw TS, Yue JJ. Morphometric comparison of the pedicle rib unit to pedicles in the thoracic spine. Spine (Phila Pa 1976) 2004;29:139-46.

10. Panjabi MM, Takata K, Goel V, et al. Thoracic human vertebrae: quantitative three-dimensional anatomy. Spine (Phila Pa 1976) 1991;16:888-901.

11. Tan SH, Teo EC, Chua HC. Quantitative three-dimensional anatomy of cervical, thoracic and lumbar vertebrae of Chi- nese Singaporeans. Eur Spine J 2004;13:137-46.

12. Berry JL, Moran JM, Berg WS, Steffee AD. A morphometric study of human lumbar and selected thoracic vertebrae. Spine (Phila Pa 1976) 1987;12:362-7.

13. Scoles PV, Linton AE, Latimer B, Levy ME, Digiovanni BF. Vertebral body and posterior element morphology: the normal spine in middle life. Spine (Phila $\mathrm{Pa}$ 1976) 1988;13:1082-6.

14. Hou S, Hu R, Shi Y. Pedicle morphology of the lower thoracic and lumbar spine in a Chinese population. Spine (Phila Pa 1976) 1993;18:1850-5.

15. Kim NH, Lee HM, Chung IH, Kim HJ, Kim SJ. Morphometric study of the pedicles of thoracic and lumbar vertebrae in Koreans. Spine (Phila Pa 1976) 1994;19:1390-4.

16. McCormack BM, Benzel EC, Adams MS, Baldwin NG, Rupp FW, Maher DJ. Anatomy of the thoracic pedicle. Neurosurgery 1995;37:303-8.

17. McLain RF, Ferrara L, Kabins M. Pedicle morphometry in the upper thoracic spine: limits to safe screw placement in older patients. Spine (Phila Pa 1976) 2002;27:2467-71.

18. Datir SP, Mitra SR. Morphometric study of the thoracic vertebral pedicle in an Indian population. Spine (Phila $\mathrm{Pa}$ 1976) 2004;29:1174-81.

19. Chadha M, Balain B, Maini L, Dhaon BK. Pedicle morphology of the lower thoracic, lumbar, and S1 vertebrae: an Indian perspective. Spine (Phila Pa 1976) 2003;28:744-9.

20. Christodoulou AG, Apostolou T, Ploumis A, Terzidis I, Hantzokos I, Pournaras J. Pedicle dimensions of the thoracic and lumbar vertebrae in the Greek population. Clin Anat 2005;18:404-8.

21. Liau KM, Yusof MI, Abdullah MS, Abdullah S, Yusof AH. Computed tomographic morphometry of thoracic pedicles: safety margin of transpedicular screw fixation in malaysian malay population. Spine (Phila Pa 1976) 2006;31:E545-50.

22. Acharya S, Dorje T, Srivastava A. Lower dorsal and lumbar pedicle morphometry in Indian population: a study of four hundred fifty vertebrae. Spine (Phila Pa 1976) 2010;35:E378-84.

23. Islam C, Sakul BU, Güzel MB. Real minimal diameter of the lower thoracic and lumbar vertebral pedicles. Clin Anat 1994;7:271-4.

24. Kim JH, Choi GM, Chang IB, Ahn SK, Song JH, Choi HC. Pedicular and extrapedicular morphometric analysis in the korean population: computed tomographic assessment relevance to pedicle and extrapedicle screw fixation in the thoracic spine. J Korean Neurosurg Soc 2009;46:181-8. 
25. Dommisse GF. The blood supply of the spinal cord: a critical vascular zone in spinal surgery. J Bone Joint Surg Br 1974;56:225-35.

26. Drake RL, Vogl W, Mitchell AW. Textbook of Gray's anatomy for students. 2nd ed. Philadelphia: Churchill Liv- ingstone Publications, 2010. p. 67-99.

27. Romanes GJ. Cunninghams manual of practical anatomy, vol. 2. 15th ed. New York: Oxford University Press, 1996. p. 3-82. 